\title{
Oligodendrocytes: Myelination and Axonal Support
}

\author{
Mikael Simons ${ }^{1,2}$ and Klaus-Armin Nave $^{3}$ \\ ${ }^{1}$ Cellular Neuroscience, Max Planck Institute of Experimental Medicine, 37075 Göttingen, Germany \\ ${ }^{2}$ Department of Neurology, University of Göttingen, 37075 Göttingen, Germany \\ ${ }^{3}$ Department of Neurogenetics, Max Planck Institute of Experimental Medicine, 37075 Göttingen, Germany \\ Correspondence: msimons@gwdg.de; nave@em.mpg.de
}

Myelinated nerve fibers have evolved to enable fast and efficient transduction of electrical signals in the nervous system. To act as an electric insulator, the myelin sheath is formed as a multilamellar membrane structure by the spiral wrapping and subsequent compaction of the oligodendroglial plasma membrane around central nervous system (CNS) axons. Current evidence indicates that the myelin sheath is more than an inert insulating membrane structure. Oligodendrocytes are metabolically active and functionally connected to the subjacent axon via cytoplasmic-rich myelinic channels for movement of macromolecules to and from the internodal periaxonal space under the myelin sheath. This review summarizes our current understanding of how myelin is generated and also the role of oligodendrocytes in supporting the long-term integrity of myelinated axons.

W hen Virchow analyzed the fine structure of the brain in the 1850s, he recognized that there were more cells within the "Nervenkitt" than astrocytes, but because of the imperfect staining methods, they remained obscure and were only named the "third element" (reviewed in Somjen 1988; Rosenbluth 1999). It was decades later that Pío del Río-Hortega (1921) applied a staining method involving silver carbonate, thereby shedding new light on the rest of the interstitial cells. These cells were found to contain numerous short processes and were named oligodendroglia and microglia. Defining features of oligodendrocytes were their small cell bodies filled with nuclei containing large amounts of chromatin, and their cellular extensions that lacked fibers but were filled with cy- toplasmic granules (Fig. 1). When the tissue was optimally preserved, the silver impregnation uncovered a tremendous complexity of extensions (Fig. 1). del Río-Hortega was able to distinguish four types of oligodendrocytes (Fig. 1): Type I cells generate many different myelin segments on small diameter axons in diverse orientations; type II cells are similar to type I in size and number, but myelin segments run in parallel to each other; type III oligodendrocytes ensheath fewer axons of larger diameter; and type IV oligodendrocytes have a cell body closely apposed to a single very large axon similar to Schwann cells. From the staining, it became clear that some of the processes run in parallel to axons and appeared to cover the axons with "myelin," a term that was introduced by Virchow already in

Editors: Ben A. Barres, Marc R. Freeman, and Beth Stevens

Additional Perspectives on Glia available at www.cshperspectives.org

Copyright (C) 2016 Cold Spring Harbor Laboratory Press; all rights reserved; doi: 10.1101/cshperspect.a020479

Cite this article as Cold Spring Harb Perspect Biol 2016;8:a020479 

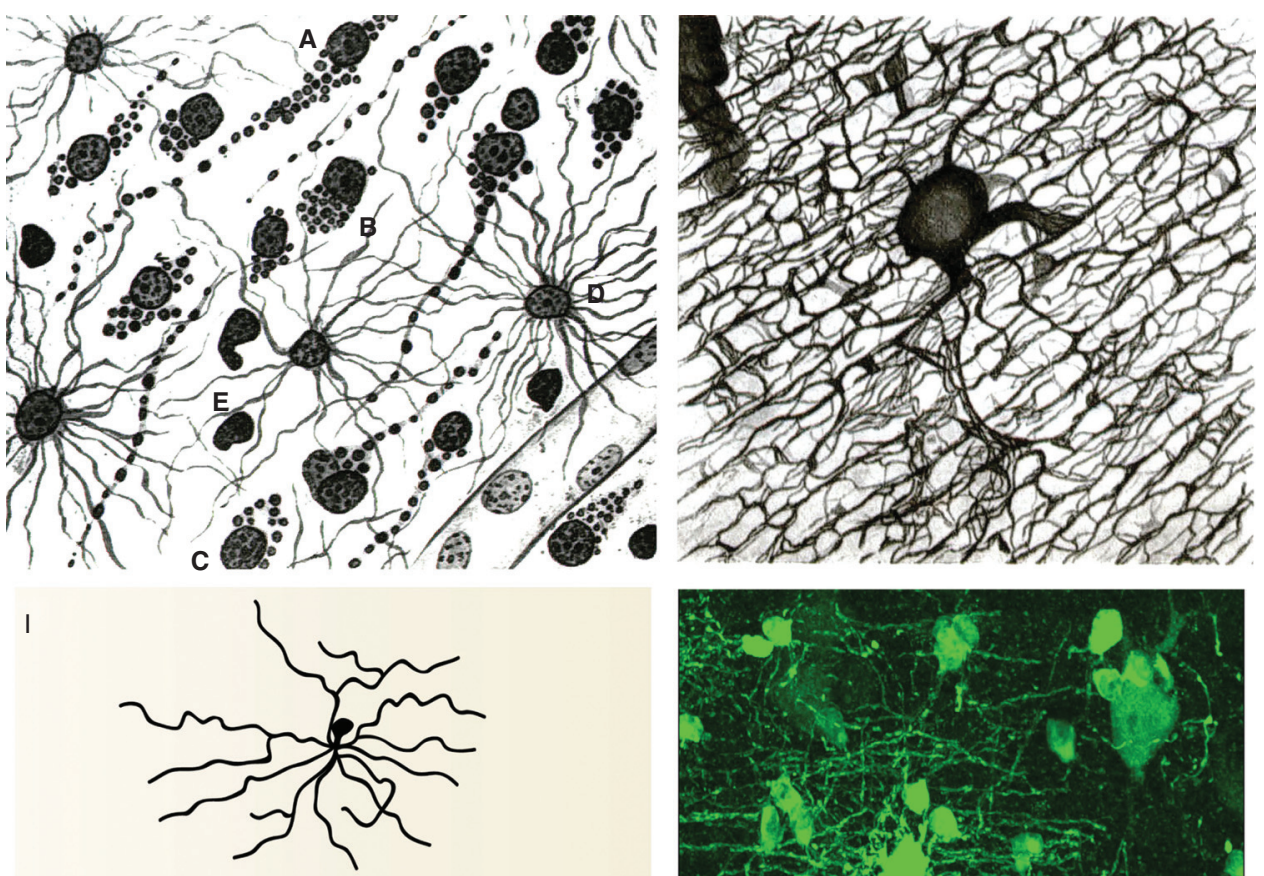

II

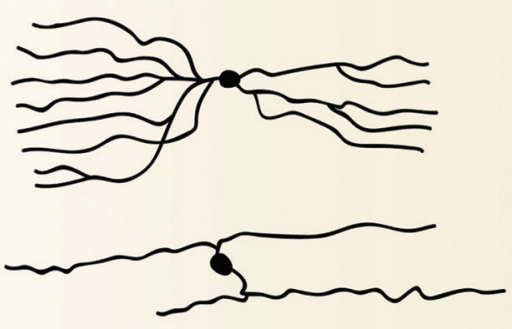

IV
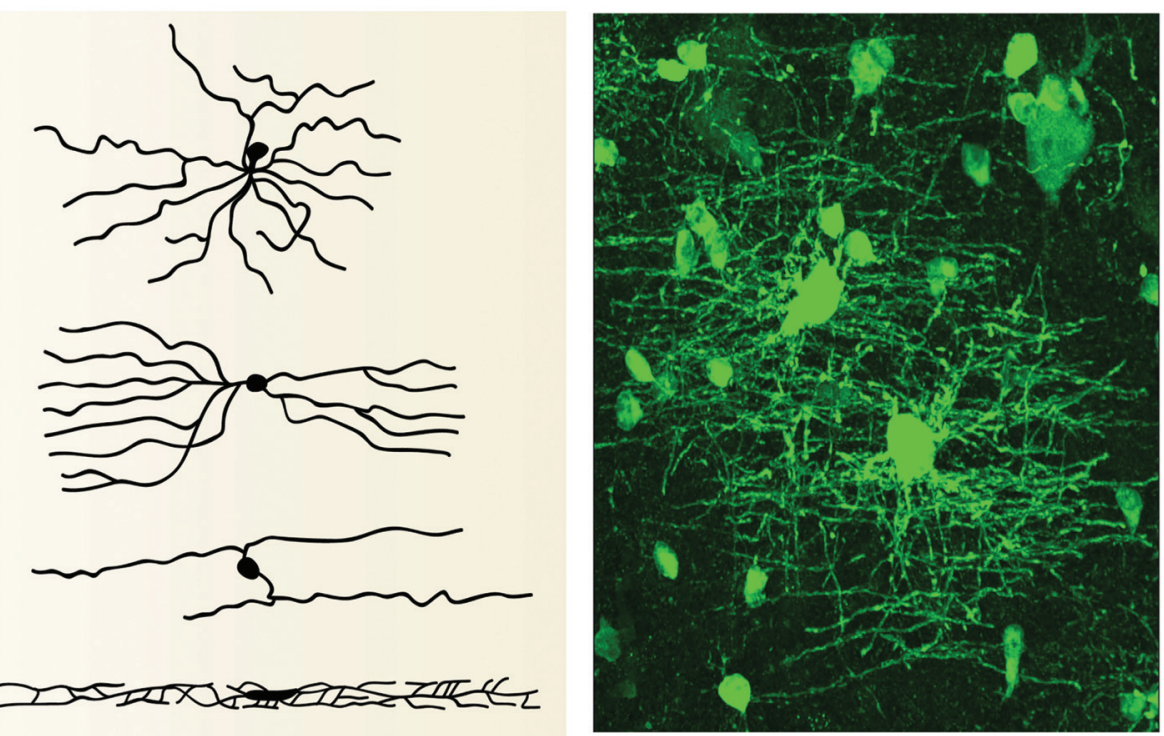

Figure 1. Morphology of oligodendroglia in the cerebellum of a cat. (Top right) Cellular processes and branches follow the orientation of the nerve fibers and form complex wraps as shown in del Río-Hortega (1921). (Top left) White matter of a newborn human brain: A, Elongated interfascicular cells filled with spherical granules of variable size; B and C, round granular cells; D, astrocytes with long processes; and E, nucleus of a microglia as shown in del Río-Hortega (1921). (Bottom left) The four types of oligodendrocytes recognized by del RíoHortega. (Bottom right) Oligodendrocytes expressing proteolipid protein (PLP)-enhanced green fluorescent protein (EGFP) in transgenic mice. Because of its bulky EGFP tag, most of it is found within the cytoplasmicrich spaces or myelin, including the myelinic channels.

1858 , long before its origin and function were known.

Penfield (1924) reinforced the view that the formation of myelin is likely the main role of oligodendrocytes. However, myelination was not considered their only function. Within the gray matter, a fraction of oligodendrocytes were termed "perineuronal" satellite cells, which did not form myelin, but were in close contact with the cell body of neurons, suggesting an interdependent relation. Some oligodendroglia were found in close association with small vessels and were, therefore, subclassified as "perivascular satellites."

The major findings that supported the role of oligodendrocytes in myelin generation were 
their high number in white matter tracts, their appearance in development at the time of myelination, and their position close to the myelin sheaths. Curiously, the large number of granules in the cytosol of oligodendrocytes, reminiscent of cells of secretory glands, was also taken as evidence for a function in myelin formation. At that time, myelin was not considered to be an extension of the oligodendroglial plasma membrane, however, but rather a fatty axonal substance secreted into the extracellular space. The importance of the "axon cylinder" for saltatory impulse propagation was well recognized, but it was the seminal work of Betty Ben Geren (1954), using electron microscopy (EM) in the chick peripheral nervous system, which showed that myelin is not axon derived, but rather a continuous membranous extension of Schwann cells. A principally similar relationship, with spiral wrapping of the glial plasma membrane around the axon, was confirmed later for oligodendrocytes in the central nervous system (CNS) (for an excellent early review, see Bunge 1968; Hildebrand et al. 1993). Together, these studies have turned oligodendrocytes and myelin from a putty-amorphous "Nervenkitt" into a fascinating study object of cell biology.

\section{MYELIN STRUCTURE}

Myelin became the subject of intense investigations with the refinement of EM, and the application of biochemistry (later, proteomics), when it was found that myelin can be physically purified from most other brain membranes (Norton and Poduslo 1973). Mouse genetics was an early link between these two levels of analysis by providing molecular insight into the myelin architecture. By EM analysis, myelin is a multilayered stack of uniformly thick membranes with a characteristic periodic structure of alternating electron-dense and -light layers, termed the "major dense line" and the "intraperiod line," respectively (Fig. 2). These are adhesion zones and represent the closely apposed cytoplasmic and extracellular myelin membrane bilayers, which appear in repeating patterns of $\sim 12 \mathrm{~nm}$ ("periodicity"). Compacted myelin provides the high electrical resistance and low capacitance that is essential for saltatory impulse propagation. At their edges, myelin lamellae are tightly connected by autotypic tight junctions between the membranes of the outer leaflet, consisting of claudin-11 (Gow et al. 1999; Morita et al. 1999). These interlamellar strands run radially through myelin, forming the so-called "radial components." Most of what we know about myelin ultrastructure is based on EM studies performed on glutaraldehyde-fixed and-dehydrated tissue, often associated with shrinkage and collapse of intracellular spaces. A recent technical advance has been (fixation-free) high-pressure freezing EM with an enhanced preservation of tissue architecture, including the cytoplasmic spaces within myelin (Mobius et al. 2008). These noncompacted regions comprise the outer and inner periaxonal "tongues" (or "lips") of myelin membranes, the "paranodal loops," and the "Schmidt-Lanterman incisures" (the latter in the peripheral nervous system). Cytoplasmic channels, reminiscent of Schmidt-Lanterman incisures, can also be found in developing myelin sheaths of the CNS, but largely disappear when myelination is completed (Snaidero et al. 2014). Another method to visualize these cytoplasmic channels within myelin (termed "myelinic channels" in the following) is to inject diffusible dyes into oligodendrocytes or transgenically express fluorescent proteins. Using the fluorescent dye Lucifer Yellow, an extensive network of interconnected cytoplasmic pockets $(\sim 1.9$ pockets per $10 \mu \mathrm{m}$ sheath length) was observed in slices of acutely isolated spinal cord (Velumian et al. 2011). During development, myelinic channels are likely to serve as tracks for the delivery of the newly synthesized membrane to the growing tip (see below). In the adult nervous system, they may provide a functional connection between the oligodendroglial soma and the periaxonal space, allowing the distribution of glial metabolites to the axonal compartment. Considering that oligodendrocytes are also interconnected through gap junctions with each other and astrocytes, glial cells may provide a functional "syncytium" within white matter tracts (Abrams and Scherer 2012; Bedner et al. 2012; NualartMarti et al. 2013). 


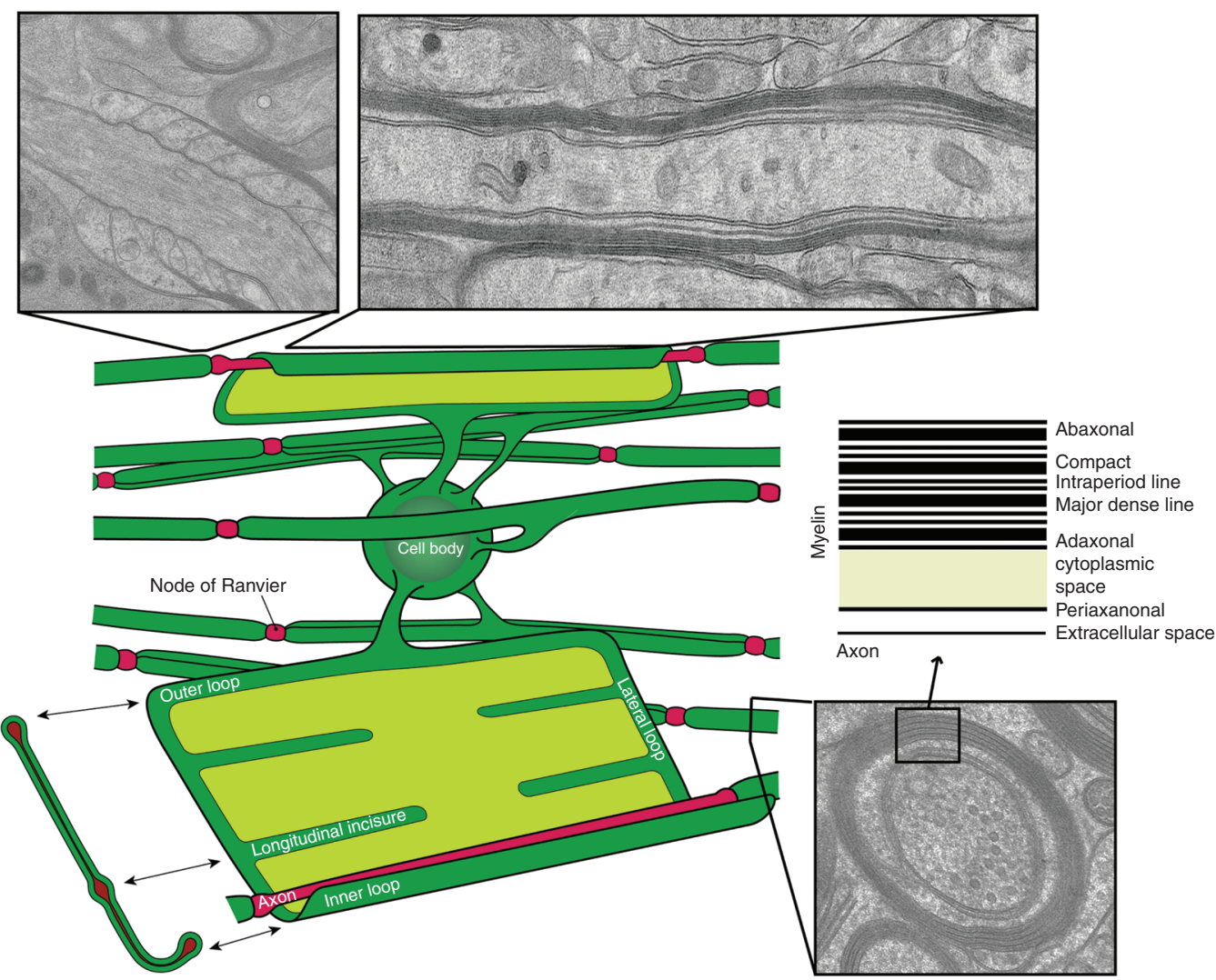

Figure 2. Schematic view of myelinating oligodendrocytes in its wrapped and conceptually "unrolled" state. Electron micrographs show (left) paranodal loops, a longitudinal view (right), and a cross-section view (bottom) of myelin. (From Aggarwal et al. 2011a; modified, with permission, from Elsevier Limited (C) 2011.)

The myelin sheath is also firmly attached to the axon at each end of an internode in which the myelin membrane never obtains a compacted structure, but terminates in the paranodal loops. These form septate junctions with the axonal surface, held together by the adhesion proteins Caspr and contactin on the axonal side and Neurofascin-155 on the glial surface (Salzer et al. 2008). In the intermodal region (i.e., between the two paranodal domains), the innermost lamellae of the myelin sheath remain noncompacted and form a cytoplasmic compartment, the adaxonal part of the myelinic channel system. It faces the periaxonal space along its length and is ideally positioned to communicate to the neuron.

Apart from its unique ultrastructure, there are several other exceptional features of myelin.
One is certainly its molecular composition. Myelin is a poorly hydrated structure, containing only $40 \%$ of water as compared with $80 \%$ in the gray matter. Myelin contains $70 \%-80 \%$ lipids (by dry weight) and there is only a small set of proteins that reside within compacted myelin, of which myelin basic protein (MBP) and PLP are most abundant. Even if recent proteome studies have uncovered many more proteins within purified myelin fractions (Werner et al. 2007; Ishii et al. 2009; Dhaunchak et al. 2010; Patzig et al. 2011; Manrique-Hoyos et al. 2012), it still holds true that the proteome of compact myelin is dominated by a few major, predominantly low molecular weight, and mostly myelin-specific proteins.

Another defining feature of myelin is its extraordinary stability. This was convincingly 
Oligodendrocytes: Myelination and Axonal Support

shown when 5000-yr-old myelin with an almost intact ultrastructure was dissected from a Tyrolean Iceman (Hess et al. 1998). The underlying molecular basis for the stability of myelin is likely its lipid composition with high levels of saturated, long-chain fatty acids, together with an enrichment of glycosphingolipids ( $~ 20 \%$ molar percentage of total lipids) and cholesterol ( $\sim 40 \%$ of molar percentage of total lipids) (O’Brien 1965; Coetzee et al. 1996). In addition, myelin comprises a high proportion of plasmalogens (etherlipids) with saturated long-chain fatty acids (Chrast et al. 2011). In fact, 20\% of the fatty acids in myelin have hydrocarbon chains longer than 18 carbon atoms $(\sim 1 \%$ in gray matter) and only $\sim 6 \%$ of the fatty acids are polyunsaturated ( $\sim 20 \%$ in gray matter). Van der Waals dispersion forces, which are generated by the interaction between methylene groups of these long and saturated hydrocarbon chains, provide the major forces that hold these molecules together. In addition, $>50 \%$ of galactosylceramide and sulfatide are hydroxylated at the 2-C atom by fatty acid 2-hydroxylase (FA2H), thereby providing additional hydroxyl groups for hydrogen bonding and, thus, increasing the packing density of lipids in myelin (Eckhardt et al. 2005; Zoller et al. 2008).

Another peculiarity of the myelin membrane is its metabolic stability. Myelin membrane components have a half-life on the order of several weeks to months. The half-life of cholesterol in myelin was estimated to be $>7-8 \mathrm{mo}$ (Smith and Eng 1965). Recently, using in vivo pulse-chase labeling of proteins synthesis with ${ }^{15} \mathrm{~N}$ isotopes, followed by mass spectrometry at various ages, myelin proteins together with histones, nucleoporins, and lamins were found to be among the most long-lived proteins in a mouse (Toyama et al. 2013). Thus, myelin is a stable system, which is in contrast to most membranes that are in highly dynamic, farfrom-equilibrium steady state (Aggarwal et al. 2011).

However, myelin is compartmentalized into structurally and biochemically distinct domains. It is likely that the noncompacted regions are much more dynamic and metabolically active than the tightly compacted regions, which lack direct access to the membrane-trafficking machinery of oligodendrocytes.

\section{MYELIN ASSEMBLY}

Most oligodendrocytes generate between 20 and 60 myelinating processes with intermodal lengths of $\sim 20 \mu \mathrm{m}-200 \mu \mathrm{m}$ and up to 100 membrane turns (Matthews and Duncan 1971; Hildebrand et al. 1993; Chong et al. 2012). When estimating the "surface" area that one oligodendrocyte would have (in terms of myelin mem-

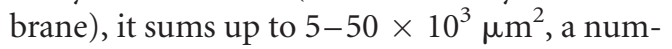
ber not reached by any other cell in our body (Pfeiffer et al. 1993; Baron and Hoekstra 2010). Myelin wrapping of single axonal segments takes only a few hours (at least in the zebrafish), which appears demanding on the machinery of protein and lipid synthesis (Czopka et al. 2013).

Myelination is a complex sequence of events that is best understood when conceptualized as separate steps, including (1) proliferation and migration of oligodendrocyte precursor cells (OPCs) in white matter tracts, (2) recognition of target axons and axon-glia signaling, (3) differentiation of OPCs into myelinating oligodendrocytes, (4) membrane outgrowth and axonal wrapping, (5) trafficking of membrane components, (6) myelin compaction, and (7) node formation. We will discuss here some aspects, but refer to comprehensive reviews for a more detailed description (Barres and Raff 1999; Baumann and Pham-Dinh 2001; Miller 2002; Emery 2010; Simons et al. 2012; Bakhti et al. 2013a; Freeman and Rowitch 2013).

First, OPCs migrate away from the neuroepithelium of the ventricular/subventricular zone of the brain into the developing white matter, in which they proliferate and form an evenly spaced network of processing-bearing cells. In vivo time-lapse imaging in transgenic zebrafish and mice show that OPCs continuously extend and retract numerous processes as they migrate and settle into their final positions (Kirby et al. 2006; Hughes et al. 2013). These dynamic and explorative processes are self-repulsive toward other OPCs and, thereby, define the uniform density and spacing of these cells. After OPCs have moved into their defined territories, their 
further paths can be very different. Although some OPCs remain in a precursor state, others will differentiate into myelin-forming oligodendrocytes. To ensure that the number of oligodendrocytes matches the number of axons to be myelinated, an excess of cells are produced, which are later eliminated by apoptosis (Raff et al. 1993; Barres and Raff 1994; Trapp et al. 1997). One mechanism that determines the final number of oligodendrocytes is the competition for limiting amounts of target-derived growth and survival factors, such as platelet-derived growth factor (PDGF)-A, fibroblast growth factor (FGF)-2, insulin-like growth factor (IGF)-1, neurotrophin (NT)-3, and ciliary neurotrophic factor (CNTF) (Barres and Raff 1994; Miller 2002). This mechanism could be confirmed in mice overexpressing PDGF-A, which caused a dramatic increase in the number of OPCs in the embryonic mouse spinal cord, followed by production of ectopic oligodendrocytes (Calver et al. 1998). This excess of oligodendrocytes is later counterbalanced by an increase of apoptosis at an immature stage of differentiation, resulting in a normal number of myelin-forming oligodendrocytes.

Maturating OPCs pass through different stages of morphological differentiation and express a number of cell-specific marker proteins and lipids (Baumann and Pham-Dinh 2001). Based on morphology and molecular phenotype, cells in this lineage can be sequentially grouped into OPCs, immature/premyelinating oligodendrocytes, and mature/myelinating oligodendrocytes. The speed of oligodendrocyte differentiation is highly variable, however. In the hindbrain, oligodendrocytes are already produced a few days after the appearance of OPCs, whereas a similar transition takes several weeks in the cerebral cortex. Although it has become clear that OPCs can persist for a long time in their immature stage, it appears that once the decision has been made to trigger differentiation, it occurs at a very rapid pace. Recent time-lapse imaging in zebrafish shows that, at least in this species, there is only a brief window for an oligodendrocyte to complete myelination (Watkins et al. 2008; Czopka et al. 2013). When myelination has started, it takes that oli- godendrocyte only $5 \mathrm{~h}$ to generate all myelin sheaths.

Because the differentiation of oligodendrocytes has to be adjusted to the developmental program of neurons, the general assumption is that neuronal signals control the transformation of OPCs into myelin-forming oligodendrocytes. However, unlike in the peripheral nervous system (PNS), in which neuregulin-1 on the axonal membrane controls myelination by Schwann cells, an equivalent single-key regulator that triggers myelination by oligodendrocytes in the CNS has not been identified. Moreover, it appears that also the relief from inhibitory neuronal signals is critical for OPCs to exit a "repressed" state (Emery 2010). These inhibitory axonal signals (e.g., Jagged, PSA-NCAM, and LINGO-1), in turn, activate various transcriptional regulators, such as Sox 5/6, Hes5, and Id $2 / 4$, which actively prevent OPCs from entering terminal differentiation (Piaton et al. 2010; Taveggia et al. 2010). Many of these inhibitory transcription factors are also controlled by microRNAs (miRNAs), histone deacetylases, and signaling pathways, of which the Wnt $/ \beta$ catenin pathway has recently emerged as a key regulator of myelin gene expression and myelination (Shin et al. 2005; Fancy et al. 2009; Budde et al. 2010; Dugas et al. 2010; Kim et al. 2010; Zhao et al. 2010; Tawk et al. 2011).

From the wealth and complexity of the signals that ultimately prevent OPCs from entering terminal differentiation, it becomes clear that the timing of oligodendrocyte differentiation is a critical step in the life of an oligodendrocyte. Electrically active neurons appear to stimulate OPC proliferation and selectively induce myelination of an active neural circuit (Gibson et al. 2014). Once the decision has been made to initiate myelination, oligodendrocytes must be properly positioned because mature oligodendrocytes appear to have very little capacity to migrate into new positions or to delay myelin synthesis. A number of "feedforward signals" have been identified that help to speed up the morphological differentiation of OPCs once the starting signal(s) has been launched. For example, microRNAs, in particular, miRNA-219 and miRNA-338, actively repress the activity of crit- 
ical transcription factors and signaling pathways, such as Sox5/6, Hes5, and PDGFR $\alpha$ (Dugas et al 2010; Zhao et al. 2010; Hudish et al. 2013). At the same time that the activity of other transcription factors, including repressors of repressors and activators of transcription, like myogenic regulatory factors (MRFs), Nxk2.2, Olig1, Sox10, YY1, and Zfp191, are turned on (He et al. 2007; Wegner 2008; Emery et al. 2009; Howng et al. 2010; Meijer et al. 2012; Bujalka et al. 2013). Once myelination has started, the PtdIns $(3,4,5) \mathrm{P} 3 /$ Akt/mTor and ERK1/2-dependent signaling pathways are essential in driving myelin formation forward until fully matured sheaths with optimal g-ratios have been generated (Flores et al. 2008; Tyler et al. 2009; Goebbels et al. 2010; Ishii et al. 2013).

Although much has been learned about the oligodendrocyte lineage progression, we know little about how oligodendrocytes decide which axon to select for myelination (Simons and Lyons 2013). One would assume that specific adhesion molecules must be expressed on the surface of axons, which are recognized by oligodendrocytes. However, evidence has been provided that target size alone can determine the initiation of myelination (Lee et al. 2012a). When OPCs were cultured in the presence of inert polystyrene fibers to model axons, they were able to ensheath such "axons," suggesting that oligodendrocytes (unlike Schwann cells) do not require axonal adhesion molecules and growth factors to initiate the formation of myelin. The caliber size appeared to be critical as fibers $<400 \mathrm{~nm}$ were rarely ensheathed. It is possible that, because of physical constraints, the ensheathing processes of oligodendrocytes are unable to navigate around axons below a specific threshold caliber. Although larger axons are preferentially myelinated in vivo, axons as small as 200-300 $\mathrm{nm}$ can be myelinated in some regions of the CNS. It is likely that oligodendrocytes receive specific signals from small-caliber axons to initiate myelination. The nonreceptor tyrosine kinase Fyn could be one of these signals as loss of Fyn causes a severe hypomyelination of such small-caliber axons without affecting myelination of larger axons (Umemori et al. 1994).
Once a particular axon has been engaged by a myelinating oligodendrocyte process, dramatic changes in plasma membrane architecture are induced. How the processes are converted into flat sheets that spread and wind along the axons to generate a multilayered stack of membranes has been difficult to address. By light microscopy, a coil of an average periodicity of 5.7-7 $\mu \mathrm{m}$ along the internodal dimension has been observed (Butt and Berry 2000; Pedraza et al. 2009; Sobottka et al. 2011; Ioannidou et al. 2012). This has led to the suggestion that either myelin extends as a coil twisting around the axon in a corkscrew motion (Pedraza et al. 2009) or myelin thickening is achieved by forming new layers on top of the inner ones in a "croissantlike" manner (Sobottka et al. 2011). Recently, by using EM of high-pressure frozen samples and three-dimensional reconstructions based on serial block-face EM, snapshots of the myelin ultrastructure have been obtained during development of the optic nerve (Snaidero et al. 2014). This analysis revealed that the innermost layers of myelin have the shortest lateral extensions, whereas the layers toward the top of the myelin sheath build up in size with each consecutive wrap. Together, the data suggest that myelin grows by two distinct but coordinated motions: the wrapping of the leading edge at the inner tongue around the axon, that is, underneath the previously deposited membrane, and the lateral extension of myelin membrane layers toward the nodal regions (Fig. 3). Thus, the lateral cytoplasmic-rich edges of each myelin layer always stay in close contact with the axonal surface and move in a continuous helical manner toward the future node in which they align and form the paranodal loops. This model implies that newly synthesized membrane material has to be transported all the way through the developing myelin sheath toward the innermost layer facing the axon. In fact, as already discussed above, there is an elaborated system of cytoplasmic channels within compacted myelin that provide a helical path for the transport of vesicles to the growth zone at the leading edge.

The different myelin components are synthesized in oligodendrocytes at several subcellular localizations and are transported by various 
M. Simons and K.-A. Nave

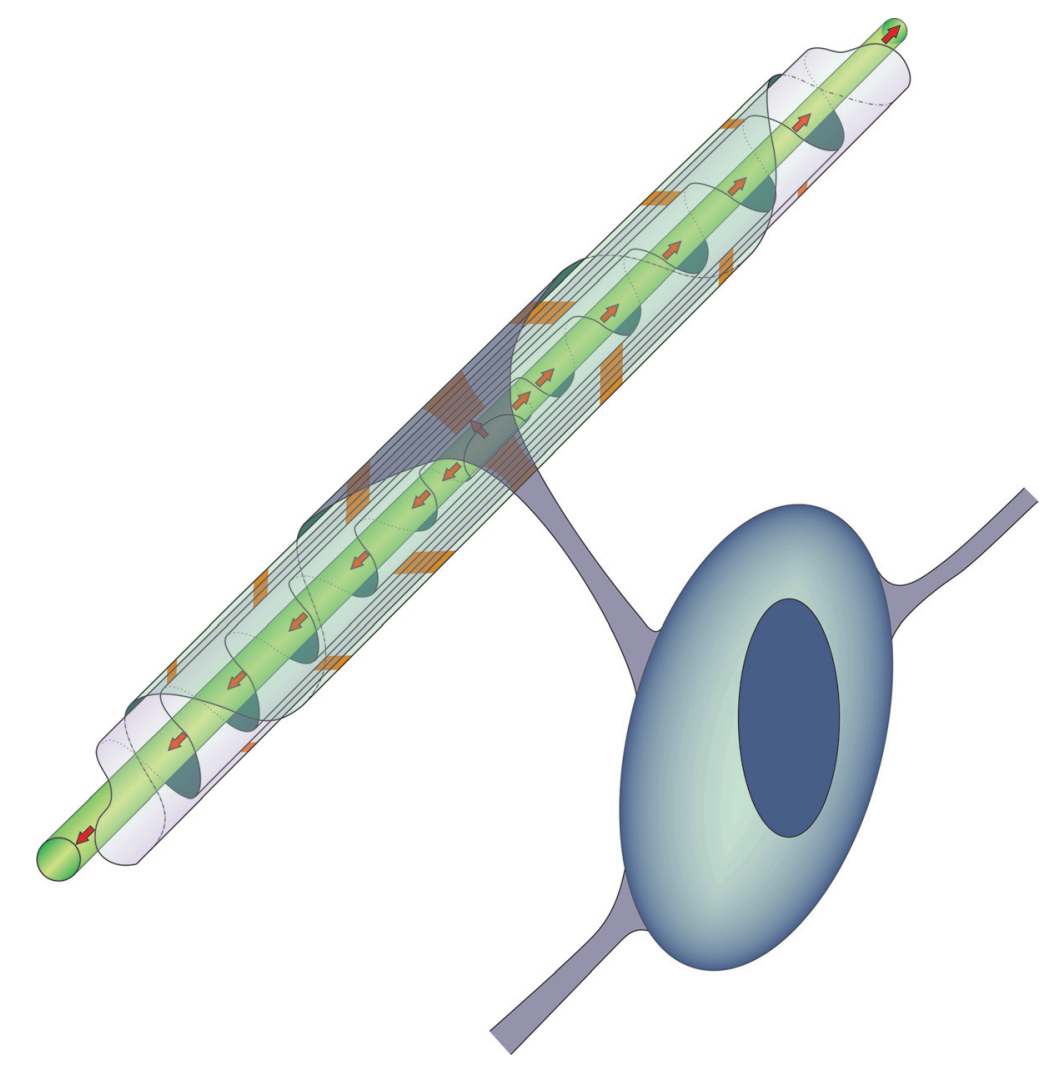

Figure 3. Model showing the direction of how myelin wraps around the axon. There are two motions: the wrapping of the leading edge at the inner tongue around the axon underneath the previously deposited membrane and the lateral extension of myelin membrane layers toward the nodal regions (for details, see Snaidero et al. 2014).

mechanisms to the growing myelin sheath. Early pulse-labeling experiment had suggested that (at least in Schwann cells) newly synthesized lipids and integral myelin proteins first reach the outer myelin membranes and then diffuse laterally, at least after the initial wraps have been made (Gould and Dawson 1976; Gould 1977). In addition to membrane transport via the biosynthetic secretory pathway, the membraneassociated protein MBP needs to be delivered to myelin, which in development occurs by the transport of its messenger RNA (mRNA) within cytoplasmic granules (Colman et al. 1982; Ainger et al. 1993). Subsequently, the local translation of MBP is initiated at the tip of the glial process, which is in contact with the axon in vivo (or in the outermost edge of the oligodendrocyte in vitro) (White et al. 2008; Laursen et al.
2011; Wake et al. 2011). Although MBP is, thus, synthesized in the distal process, that is, closest to the axon, myelin compaction is mediated by MBP progresses from the outside to the inside of the sheath, namely, proximal to distal (Snaidero et al. 2014). It is obvious that if the sites of MBP translation and compaction are spatially separated, there must be a mechanism in place that prevents membrane compaction at the site of MBP synthesis. The myelin protein CNP1 appears to be such a factor that delays myelin compaction. In mice lacking CNP1, myelin compaction proceeds faster and extends to the innermost layers of the myelin sheath, whereas transgenic overexpression of CNP1 results in areas of myelin that lack compaction (Gravel et al. 1996; Snaidero et al. 2014). Thus, the equilibrium of CNP1 and MBP levels seems to reg- 
ulate the speed of compaction in early development.

Once MBP is bound to two adjacent cytoplasmic membrane surfaces, it appears to "polymerize" by lateral interactions with previously deposited MBP "monomers," thereby driving membrane zippering at the cytoplasmic surfaces of the myelin bilayer (Aggarwal et al. 2013). The self-association of high-order aggregates is triggered by membrane binding of MBP, which results in charge neutralization and major conformational changes of the protein (Harauz et al. 2009; Aggarwal et al. 2013; Bakhti et al. 2013). One major consequence of the formation of MBP polymers is the depletion of most peripheral and membrane-associated proteins from compacted myelin. This occurs by MBP-mediated protein extrusion and generation of a diffusion barrier, which limits the entry of proteins with larger cytoplasmic domains (Aggarwal et al. 2011).

Compact myelin becomes a protein-poor membrane, lacking major glycoproteins at the extracellular leaflet, which is likely to uncover weak (generic) forces that promote the association of two bilayers at their extracellular surface (Bakhti et al. 2013). In addition, with the maturation of oligodendrocytes, the plasma membrane undergoes major transformations of its structure. Whereas OPCs are covered by a dense layer of large and negatively charged self-repulsive oligosaccharides, the compacted myelin of fully matured oligodendrocytes lacks most of these glycoproteins and complex glycolipids. Such a conversion may contribute to the transformation of oligodendrocyte lineage cells from the self-avoiding and "repulsive" OPCs that tile the entire CNS to "sticky" oligodendrocytes, which ensheath axons with a multilayered stack of self-associating membranes.

\section{METABOLIC SUPPORT OF AXON FUNCTION}

Once myelination is completed, the developmentally important cytosolic channels decrease in size, but remain as a significant compartment of (noncompacted) myelin, which can be visualized, for example, by dye injections, the expres- sion of fluorescent proteins (Fig. 1), or highpressure freezing EM. This cytosolic space connects the mature oligodendroglial soma to the innermost tip of the oligodendrocyte process (Fig. 2). As a "myelinic channel," this tube-like cytosolic compartment (also termed the "inner lip") runs in parallel to the thin extracellular periaxonal space in which it faces the axonal internode along its length (Nave 2010). It is filled with a plethora of soluble and membrane-associated myelin proteins and a molecular complexity that outreaches, by far, the proteome of compacted myelin (Roth et al. 2006; Werner et al. 2007; Ishii et al. 2009; Jahn et al. 2009). Moreover, the detection of microtubules and multivesicular bodies within the myelinic channel by EM (mostly in the paranodal loops and the Schmitt-Lanterman incisures of myelin in the peripheral nervous system) suggests that motor-driven transport processes in this compartment are maintained throughout adult life. Apparently, the fine structure of noncompacted myelin preserves functional axonal integrity as compact myelin not only insulates axons electrically, but also shields the axonal compartment and limits rapid access to metabolites in the extracellular space.

Loss of the normal fine structure of myelin can cause late-onset axonal degeneration and even premature death, as shown in mouse mutants that lack certain myelin-specific proteins (Griffiths et al. 1998). For example, absence of the membrane-anchored protein CNP1 (which normally prevents premature myelin compaction during development; see above) does not alter myelination per se, but is associated with secondary transport problems in the axonal compartment after myelination has been completed. One contributing mechanism could be the abnormal closure of myelinic channels by abnormal "compaction," which might directly or indirectly interfere with efficient metabolic coupling of oligodendrocytes and axons. The resulting pathology is indicative of axonal energy deficits and is followed by widespread axonal loss and premature death in mice (LappeSiefke et al. 2003; Edgar and Nave 2009). Even $50 \%$ reduced expression of CNP1 (in heterozygous mouse mutants) interferes with long-term 
maintenance of white matter tracts. In this case, CNP1 deficiency leads to axonal loss and significant neuroinflammation only at an older age when mice also become behaviorally abnormal (Hagemeyer et al. 2012).

Indeed, recent genetic evidence suggests that oligodendrocytes and axons are metabolically coupled (Fig. 4). Mice, in which oligodendrocytes lack mitochondrial respiration (Fünfschilling et al. 2012), showed that with myelination the energy metabolism of developing oligodendrocytes switches. Although oligodendrocytes in development import glucose and lactate (Rinholm et al. 2011) to allow rapid myelination, building on the synthesis of large amounts of lipids, after myelination the same oligodendrocytes can survive by glycolysis only, without signs of demyelination or degeneration. In fact, oligodendroglia-derived lactate can be readily metabolized within myelinated tracts, in which axons were shown to efficiently take up lactate for mitochondrial ATP production (Fünfschil- ling et al. 2012). This mechanism of oligodendroglial support requires, in addition to glucose import through glial glucose transporters (GLUT1), the subsequent release of lactate (and/or pyruvate) into the periaxonal space, which is a function of the monocarboxylate transporter MCT1 (Lee et al. 2012). Interestingly, even 50\% reduced expression of MCT1 (in heterozygous mouse mutants) interferes with long-term maintenance of myelinated axons (Lee et al. 2012), similar in phenotype to axonal degeneration caused by oligodendrocyte-specific defects (Griffiths et al. 1998; Lappe-Siefke et al. 2003). Thus, it is plausible that either the delivery of metabolites by diffusion through myelinic channels and MCTs or the deposition and turnover of MCTs themselves can be impaired if myelin is structurally perturbed or becomes secondarily disrupted, such as in demyelinating diseases. On the other hand, even a severe developmental dysmyelination, such as in "shiverer" (MBP-deficient) mice, is compat-

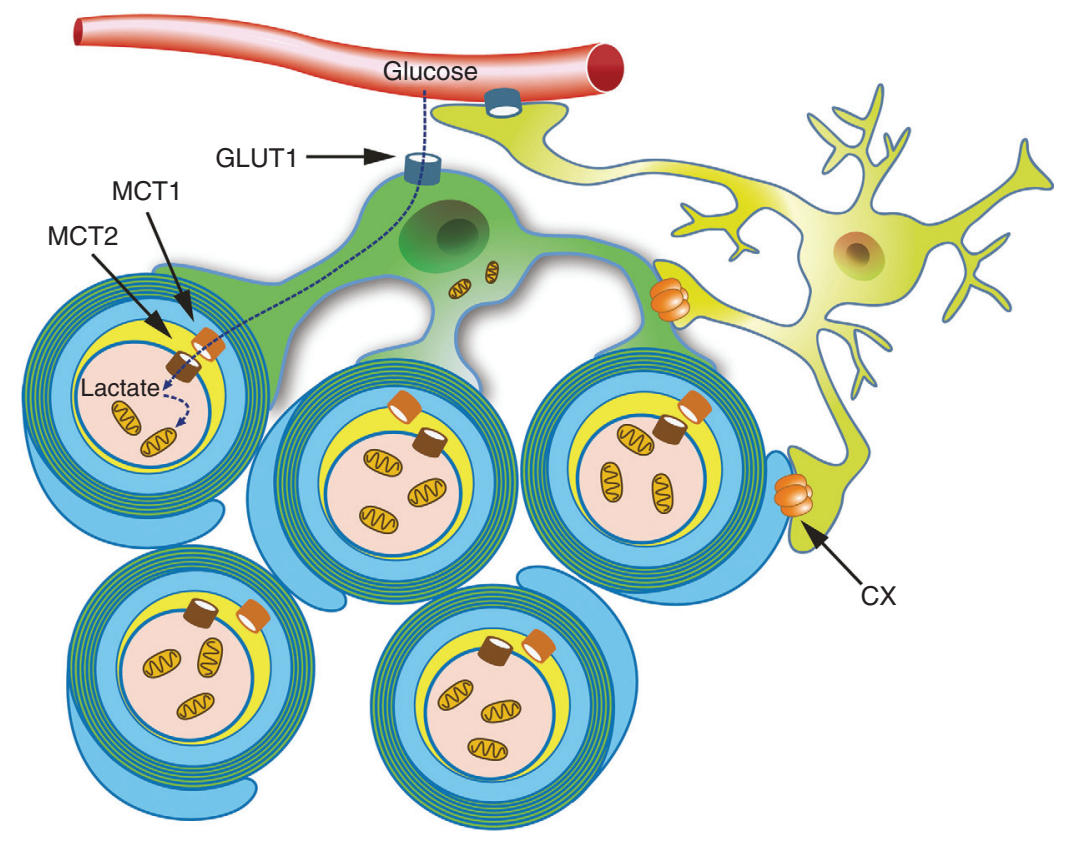

Figure 4. Schematic depiction of an oligodendrocyte that takes up blood-derived glucose and delivers glycolysis products (pyruvate/lactate) via monocarboxylate transporters (MCT1 and MCT2) to myelinated axons. Oligodendrocytes and myelin membranes are also coupled by gap junctions to astrocytes and, thus, indirectly to the blood-brain barrier. CX, Connexin. (From Saab et al. 2013; modified, with permission, from Elsevier Limited (C) 2013.) 
ible with axon function and survival, presumably as long as critical metabolic interactions remain intact (Griffiths et al. 1998). In fact, comparing different myelin disease models, it appears that for the maintenance of axon function, no myelin is better than defective myelin when associated with a loss of axon-glia metabolic coupling. Axonal energy metabolism is important, but unlikely the only aspect of intermediate metabolism in the axonal compartment dependent on associated glial cells. This is also suggested by very recent observations in mice with LKB1-deficient Schwann cells showing late-onset axonal degeneration even in the presence of elevated lactate (Beirowski et al. 2014).

\section{CONCLUDING REMARKS}

The formation of myelin is one of the most complex transformations of a plasma membrane that comprises timely coordinated cellcell interactions with reciprocal intercellular signaling events, the wrapping and extension of the glial plasma membrane around the axon, and the extrusion of cytoplasm from newly generated multilamellar membrane stacks. Each of these events represents a fascinating area of cellular neuroscience with relevance not only for our understanding of normal physiology, but also for various white matter diseases. Whereas the myelin sheath has been regarded for a long time as an inert insulating structure, it has now become clear that myelin is "alive" and metabolically active with cytoplasmic-rich pathways, myelinic channels, for movement of macromolecules into the periaxonal space. The myelin sheath and its subjacent axon need to be regarded as one functional unit that is not only morphological, but also metabolically coupled. In the future, we need to also understand whether macromolecules are exchanged between neurons and glia. Over the past, it has become clear that myelin can undergo significant structural changes in adulthood (Young et al. 2013). Myelin seems to be dynamically regulated by experience both during development and in adult life, thus, the extent of myelin sheath formation may also serve as a form of plasticity to adapt brain function to environmental stimuli (Fields
2008; Liu et al. 2012; Makinodan et al. 2012; Mangin et al. 2012; Young et al. 2013). Clearly, identifying the molecular mechanisms that regulate myelin formation and metabolic pathways within myelin are likely to be key areas for further study.

\section{ACKNOWLEDGMENTS}

We thank F. Kirchhoff for the image showing PLP-EGFP in transgenic mice, and N. Snaidero and W. Möbius for electron microscopy. We also thank J. Edgar, S. Goebbels, B. Hamprecht, J. Hirrlinger, A. Saab, G. Saher, and H. Werner for frequent discussions. Work in the authors' laboratory is supported by Grants from the German Research Foundation (SI 746/9-1 and 101; TRR43), the Tschira-Stiftung, E-Rare Program (BMBF) (to M.S.), and the Deutsche Forschungsgemeinschaft (Research Center Molecular Physiology of the Brain, CNMPB), BMBF (Leukonet), and by a European Research Council Advanced grant (to K.-A.N.)

\section{REFERENCES}

Abrams CK, Scherer SS. 2012. Gap junctions in inherited human disorders of the central nervous system. Biochim Biophys Acta 1818: 2030-2047.

Aggarwal S, Yurlova L, Simons M. 2011a. Central nervous system myelin: Structure, synthesis and assembly. Trends Cell Biol 21: 585-593.

Aggarwal S, Yurlova L, Snaidero N, Reetz C, Frey S, Zimmermann J, Pahler G, Janshoff A, Friedrichs J, Muller DJ, et al. 2011b. A size barrier limits protein diffusion at the cell surface to generate lipid-rich myelin-membrane sheets. Dev Cell 21: 445-456.

Aggarwal S, Snaidero N, Pahler G, Frey S, Sanchez P, Zweckstetter M, Janshoff A, Schneider A, Weil MT, Schaap IA, et al. 2013. Myelin membrane assembly is driven by a phase transition of myelin basic proteins into a cohesive protein meshwork. PLoS Biol 11: e1001577.

Ainger K, Avossa D, Morgan F, Hill SJ, Barry C, Barbarese E, Carson JH. 1993. Transport and localization of exogenous myelin basic protein mRNA microinjected into oligodendrocytes. J Cell Biol 123: 431-441.

Bakhti M, Aggarwal S, Simons M. 2013a. Myelin architecture: Zippering membranes tightly together. Cell Mol Life Sci 71: 1265-1277.

Bakhti M, Snaidero N, Schneider D, Aggarwal S, Mobius W, Janshoff A, Eckhardt M, Nave K-A, Simons M. 2013b. Loss of electrostatic cell-surface repulsion mediates myelin membrane adhesion and compaction in the central nervous system. Proc Natl Acad Sci 110: 3143-3148. 
Baron W, Hoekstra D. 2010. On the biogenesis of myelin membranes: Sorting, trafficking and cell polarity. FEBS Lett 584: 1760-1770.

Barres BA, Raff MC. 1994. Control of oligodendrocyte number in the developing rat optic nerve. Neuron 12 935-942.

Barres BA, Raff MC. 1999. Axonal control of oligodendrocyte development. J Cell Biol 147: 1123-1128.

Baumann N, Pham-Dinh D. 2001. Biology of oligodendrocyte and myelin in the mammalian central nervous system. Physiol Rev 81: 871-927.

Bedner P, Steinhauser C, Theis M. 2012. Functional redundancy and compensation among members of gap junction protein families? Biochim Biophys Acta 1818: 1971 1984.

Beirowski B, Babetto E, Golden JP, Chen YJ, Yang K, Gross RW, Patti GJ, Milbrandt J. 2014. Metabolic regulator LKB1 is crucial for Schwann cell-mediated axon maintenance. Nat Neurosci 17: 1351-1361.

Ben Geren B. 1954. The formation from the Schwann cell surface of myelin in the peripheral nerves of chick embryos. Exp Cell Res 7: 558-562.

Budde H, Schmitt S, Fitzner D, Opitz L, Salinas-Riester G, Simons M. 2010. Control of oligodendroglial cell number by the miR-17-92 cluster. Development 137: 2127-2132.

Bujalka H, Koenning M, Jackson S, Perreau VM, Pope B, Hay CM, Mitew S, Hill AF, Lu QR, Wegner M, et al. 2013. MYRF is a membrane-associated transcription factor that autoproteolytically cleaves to directly activate myelin genes. PLoS Biol 11: e1001625.

Bunge RP. 1968. Glial cells and the central myelin sheath. Physiol Rev 48: 197-251.

Butt AM, Berry M. 2000. Oligodendrocytes and the control of myelination in vivo: New insights from the rat anterior medullary velum. J Neurosci Res 59: 477-488.

Calver AR, Hall AC, Yu WP, Walsh FS, Heath JK, Betsholtz C, Richardson WD. 1998. Oligodendrocyte population dynamics and the role of PDGF in vivo. Neuron 20: 869882.

Chong SY, Rosenberg SS, Fancy SP, Zhao C, Shen YA, Hahn AT, McGee AW, Xu X, Zheng B, Zhang LI, et al. 2012. Neurite outgrowth inhibitor Nogo-A establishes spatial segregation and extent of oligodendrocyte myelination. Proc Natl Acad Sci 109: 1299-1304.

Chrast R, Saher G, Nave K-A, Verheijen MH. 2011. Lipid metabolism in myelinating glial cells: Lessons from human inherited disorders and mouse models. J Lipid Res 52: 419-434.

Coetzee T, Fujita N, Dupree J, Shi R, Blight A, Suzuki K, Popko B. 1996. Myelination in the absence of galactocerebroside and sulfatide: Normal structure with abnormal function and regional instability. Cell 86: 209-219.

Colman DR, Kreibich G, Frey AB, Sabatini DD. 1982. Synthesis and incorporation of myelin polypeptides into CNS myelin. J Cell Biol 95: 598-608.

Czopka T, Ffrench-Constant C, Lyons DA. 2013. Individual oligodendrocytes have only a few hours in which to generate new myelin sheaths in vivo. Dev Cell 25: 599-609.

del Río-Hortega P. 1921. La glía de escasa radiaciones (oligodendroglia) [Glia with many processes (oligodendroglia)]. Trab Lab Histol Patol 1-15: 1-43.
Dhaunchak AS, Huang JK, De Faria Junior O, Roth AD, Pedraza L, Antel JP, Bar-Or A, Colman DR. 2010. A proteome map of axoglial specializations isolated and purified from human central nervous system. Glia 58: 19491960.

Dugas JC, Cuellar TL, Scholze A, Ason B, Ibrahim A, Emery B, Zamanian JL, Foo LC, McManus MT, Barres BA. 2010. Dicer1 and miR-219 are required for normal oligodendrocyte differentiation and myelination. Neuron 65: 597-611.

Eckhardt M, Yaghootfam A, Fewou SN, Zoller I, Gieselmann V. 2005. A mammalian fatty acid hydroxylase responsible for the formation of $\alpha$-hydroxylated galactosylceramide in myelin. Biochem J 388: 245-254.

Edgar JM, Nave K-A. 2009. The role of CNS glia in preserving axon function. Curr Opin Neurobiol 19: 498-504.

Edgar JM, McCulloch MC, Montague P, Brown AM, Thilemann S, Pratola L, Gruenenfelder FI, Griffiths IR, Nave K-A. 2010. Demyelination and axonal preservation in a transgenic mouse model of Pelizaeus-Merzbacher disease. $E M B O \mathrm{Mol}$ Med 2: 42-50.

Emery B. 2010. Regulation of oligodendrocyte differentiation and myelination. Science 330: 779-782.

Emery B, Agalliu D, Cahoy JD, Watkins TA, Dugas JC, Mulinyawe SB, Ibrahim A, Ligon KL, Rowitch DH, Barres BA. 2009. Myelin gene regulatory factor is a critical transcriptional regulator required for CNS myelination. Cell 138: $172-185$.

Fancy SP, Baranzini SE, Zhao C, Yuk DI, Irvine KA, Kaing S, Sanai N, Franklin RJ, Rowitch DH. 2009. Dysregulation of the Wnt pathway inhibits timely myelination and remyelination in the mammalian CNS. Genes Dev 23: 1571-1585.

Fields RD. 2008. White matter in learning, cognition and psychiatric disorders. Trends Neurosci 31: 361-370.

Flores AI, Narayanan SP, Morse EN, Shick HE, Yin X, Kidd G, Avila RL, Kirschner DA, Macklin WB. 2008. Constitutively active Akt induces enhanced myelination in the CNS. J Neurosci 28: 7174-7183.

Freeman MR, Rowitch DH. 2013. Evolving concepts of gliogenesis: A look way back and ahead to the next 25 years. Neuron 80: 613-623.

Funfschilling U, Supplie LM, Mahad D, Boretius S, Saab AS, Edgar J, Brinkmann BG, Kassmann CM, Tzvetanova ID, Mobius W, et al. 2012. Glycolytic oligodendrocytes maintain myelin and long-term axonal integrity. Nature 485: 517-521.

Gibson EM, Purger D, Mount CW, Goldstein AK, Lin GL, Wood LS, Inema I, Miller SE, Bieri G, Zuchero JB, et al. 2014. Neuronal activity promotes oligodendrogenesis and adaptive myelination in the mammalian brain. Science 344: 1252304.

Goebbels S, Oltrogge JH, Kemper R, Heilmann I, Bormuth I, Wolfer S, Wichert SP, Mobius W, Liu X, Lappe-Siefke C, et al. 2010. Elevated phosphatidylinositol 3,4,5-trisphosphate in glia triggers cell-autonomous membrane wrapping and myelination. J Neurosci 30: 8953-8964.

Gould RM. 1977. Incorporation of glycoproteins into peripheral nerve myelin. J Cell Biol 75: 326-338. 
Gould RM, Dawson RM. 1976. Incorporation of newly formed lecithin into peripheral nerve myelin. J Cell Biol 68: $480-496$.

Gow A, Southwood CM, Li JS, Pariali M, Riordan GP, Brodie SE, Danias J, Bronstein JM, Kachar B, Lazzarini RA. 1999. CNS myelin and sertoli cell tight junction strands are absent in Osp/claudin-11 null mice. Cell 99: 649659.

Gravel M, Peterson J, Yong VW, Kottis V, Trapp B, Braun PE. 1996. Overexpression of $2^{\prime}, 3^{\prime}$-cyclic nucleotide $3^{\prime}$-phosphodiesterase in transgenic mice alters oligodendrocyte development and produces aberrant myelination. Mol Cell Neurosci 7: 453-466.

Griffiths I, Klugmann M, Anderson T, Yool D, Thomson C, Schwab MH, Schneider A, Zimmermann F, McCulloch $\mathrm{M}$, Nadon N, et al. 1998. Axonal swellings and degeneration in mice lacking the major proteolipid of myelin. Science 280: 1610-1613.

Hagemeyer N, Goebbels S, Papiol S, Kästner A, Hofer S, Begemann M, Gerwig UC, Boretius S, Wieser GL, Ronnenberg A, et al. 2012. A myelin gene causative of a catatonia-depression syndrome upon aging. $Е M B O \mathrm{Mol}$ Med 4: 528-539.

Harauz G, Ladizhansky V, Boggs JM. 2009. Structural polymorphism and multifunctionality of myelin basic protein. Biochemistry 48: 8094-8104.

He Y, Dupree J, Wang J, Sandoval J, Li J, Liu H, Shi Y, Nave K-A, Casaccia-Bonnefil P. 2007. The transcription factor Yin Yang 1 is essential for oligodendrocyte progenitor differentiation. Neuron 55: 217-230.

Hess MW, Kirschning E, Pfaller K, Debbage PL, Hohenberg H, Klima G. 1998. 5000-year-old myelin: Uniquely intact in molecular configuration and fine structure. Curr Biol 8: R512-R513.

Hildebrand C, Remahl S, Persson H, Bjartmar C. 1993. Myelinated nerve fibres in the CNS. Prog Neurobiol 40: 319-384.

Howng SY, Avila RL, Emery B, Traka M, Lin W, Watkins T, Cook S, Bronson R, Davisson M, Barres BA, et al. 2010. ZFP191 is required by oligodendrocytes for CNS myelination. Genes Dev 24: 301-311.

Hudish LI, Blasky AJ, Appel B. 2013. miR-219 regulates neural precursor differentiation by direct inhibition of apical par polarity proteins. Dev Cell 27: 387-398.

Hughes EG, Kang SH, Fukaya M, Bergles DE. 2013. Oligodendrocyte progenitors balance growth with self-repulsion to achieve homeostasis in the adult brain. Nat Neurosci 16: 668-676.

Ioannidou K, Anderson KI, Strachan D, Edgar JM, Barnett SC. 2012. Time-lapse imaging of the dynamics of CNS glial-axonal interactions in vitro and ex vivo. PLoS ONE 7: e30775.

Ishii A, Dutta R, Wark GM, Hwang SI, Han DK, Trapp BD, Pfeiffer SE, Bansal R. 2009. Human myelin proteome and comparative analysis with mouse myelin. Proc Natl Acad Sci 106: 14605-14610.

Ishii A, Fyffe-Maricich SL, Furusho M, Miller RH, Bansal R. 2013. ERK1/ERK2 MAPK signaling is required to increase myelin thickness independent of oligodendrocyte differentiation and initiation of myelination. J Neurosci 32: $8855-8864$.
Jahn O, Tenzer S, Werner HB. 2009. Myelin proteomics: Molecular anatomy of an insulating sheath. Mol Neurobiol 40: 55-72.

Kassmann CM, Lappe-Siefke C, Baes M, Brugger B, Mildner A, Werner HB, Natt O, Michaelis T, Prinz M, Frahm J, et al. 2007. Axonal loss and neuroinflammation caused by peroxisome-deficient oligodendrocytes. Nat Genet 39: 969-976.

Kim JY, Shen S, Dietz K, He Y, Howell O, Reynolds R, Casaccia P. 2010. HDAC1 nuclear export induced by pathological conditions is essential for the onset of axonal damage. Nat Neurosci 13: 180-189.

Kirby BB, Takada N, Latimer AJ, Shin J, Carney TJ, Kelsh RN, Appel B. 2006. In vivo time-lapse imaging shows dynamic oligodendrocyte progenitor behavior during zebrafish development. Nat Neurosci 9: 1506-1511.

Lappe-Siefke C, Goebbels S, Gravel M, Nicksch E, Lee J, Braun PE, Griffiths IR, Nave K-A. 2003. Disruption of Cnp1 uncouples oligodendroglial functions in axonal support and myelination. Nat Genet 33: 366-374.

Laursen LS, Chan CW, Ffrench-Constant C. 2011. Translation of myelin basic protein mRNA in oligodendrocytes is regulated by integrin activation and hnRNP-K. J Cell Biol 192: 797-811.

Lee S, Leach MK, Redmond SA, Chong SY, Mellon SH, Tuck SJ, Feng ZQ, Corey JM, Chan JR. 2012a. A culture system to study oligodendrocyte myelination processes using engineered nanofibers. Nat Methods 9: 917-922.

Lee Y, Morrison BM, Li Y, Lengacher S, Farah MH, Hoffman PN, Liu Y, Tsingalia A, Jin L, Zhang PW, et al. 2012b. Oligodendroglia metabolically support axons and contribute to neurodegeneration. Nature 487: 443-448.

Liu J, Dietz K, Deloyht JM, Pedre X, Kelkar D, Kaur J, Vialou V, Lobo MK, Dietz DM, Nestler EJ, et al. Impaired adult myelination in the prefrontal cortex of socially isolated mice. 2012. Nat Neurosci 15: 1621-1623.

Makinodan M, Rosen KM, Ito S, Corfas G. 2012. A critical period for social experience-dependent oligodendrocyte maturation and myelination. Science 337: $1357-$ 1360.

Mangin JM, Li P, Scafidi J, Gallo V. 2012. Experience-dependent regulation of NG2 progenitors in the developing barrel cortex. Nat Neurosci 15: 1192-1194.

Manrique-Hoyos N, Jurgens T, Gronborg M, Kreutzfeldt M, Schedensack M, Kuhlmann T, Schrick C, Bruck W, Urlaub H, Simons M, et al. 2012. Late motor decline after accomplished remyelination: Impact for progressive multiple sclerosis. Ann Neurol 71: 227-244.

Matthews MA, Duncan D. 1971. A quantitative study of morphological changes accompanying the initiation and progress of myelin production in the dorsal funiculus of the rat spinal cord. J Comp Neurol 142: 1-22.

Meijer DH, Kane MF, Mehta S, Liu H, Harrington E, Taylor CM, Stiles CD, Rowitch DH. 2012. Separated at birth? The functional and molecular divergence of OLIG1 and OLIG2. Nat Rev Neurosci 13: 819-831.

Miller RH. 2002. Regulation of oligodendrocyte development in the vertebrate CNS. Prog Neurobiol 67: 451-467.

Mobius W, Cooper B, Kaufmann WA, Imig C, Ruhwedel T, Snaidero N, Saab AS, Varoqueaux F. 2008. Electron mi- 
croscopy of the mouse central nervous system. Methods Cell Biol 96: 475-512.

Morita K, Sasaki H, Fujimoto K, Furuse M, Tsukita S, 1999. Claudin-11/OSP-based tight junctions of myelin sheaths in brain and Sertoli cells in testis. J Cell Biol 145: 579-588.

Nave K-A. 2010. Myelination and the trophic support of long axons. Nat Rev Neurosci 11: 275-283.

Norton WT, Poduslo SE. 1973. Myelination in rat brain: Method of myelin isolation. J Neurochem 21: 749-757.

Nualart-Marti A, Solsona C, Fields RD. 2013. Gap junction communication in myelinating glia. Biochim Biophys Acta 1828: 69-78.

O’Brien JS. 1965. Stability of the myelin membrane. Science 147: 1099-1107.

Patzig J, Jahn O, Tenzer S, Wichert SP, de MonasterioSchrader P, Rosfa S, Kuharev J, Yan K, Bormuth I, Bremer J, et al. 2011. Quantitative and integrative proteome analysis of peripheral nerve myelin identifies novel myelin proteins and candidate neuropathy loci. J Neurosci 31: 16369-16386.

Pedraza L, Huang JK, Colman D. 2009. Disposition of axonal Caspr with respect to glial cell membranes: Implications for the process of myelination. J Neurosci Res 87: 3480-3491.

Penfield W. 1924. Oligodendroglia and its relation to classical neurogha. Brain 47: 430-452.

Pfeiffer SE, Warrington AE, Bansal R. 1993. The oligodendrocyte and its many cellular processes. Trends Cell Biol 3: 191-197.

Piaton G, Gould RM, Lubetzki C. 2010. Axon-oligodendrocyte interactions during developmental myelination, demyelination and repair. J Neurochem 114: $1243-$ 1260.

Raff MC, Barres BA, Burne JF, Coles HS, Ishizaki Y, Jacobson MD. 1993. Programmed cell death and the control of cell survival: Lessons from the nervous system. Science 262: 695-700.

Rinholm JE, Hamilton NB, Kessaris N, Richardson WD, Bergersen LH, Attwell D. 2011. Regulation of oligodendrocyte development and myelination by glucose and lactate. J Neurosci 3: 538-548.

Rosenbluth J. 1999. A brief history of myelinated nerve fibers: One hundred and fifty years of controversy. J Neurocytol 28: 251-262.

Roth AD, Ivanova A, Colman DR. 2006. New observations on the compact myelin proteome. Neuron Glia Biol 2: $15-21$.

Saab AS, Tzvetanova ID, Nave K-A. 2013. The role of myelin and oligodendrocytes in axonal energy metabolism. Curr Opin Neurobiol 23: 1065-1072.

Salzer JL, Brophy PJ, Peles E. 2008. Molecular domains of myelinated axons in the peripheral nervous system. Glia 56: $1532-1540$.

Shin JY, Fang ZH, Yu ZX, Wang CE, Li SH, Li XJ. 2005. Expression of mutant huntingtin in glial cells contributes to neuronal excitotoxicity. J Cell Biol 171: 10011012.

Simons M, Lyons DA. 2013. Axonal selection and myelin sheath generation in the central nervous system. Curr Opin Cell Biol 25: 512-519.
Simons M, Snaidero N, Aggarwal S. 2012. Cell polarity in myelinating glia: From membrane flow to diffusion barriers. Biochim Biophys Acta 1821: 1146-1153.

Smith ME, Eng LF. 1965. The turnover of the lipid components of myelin. J Am Oil Chem Soc 42: 1013-1018.

Snaidero N, Möbius W, Czopka T, Hekking LHP, Mathisen C, Verkleij D, Goebbels S, Edgar J, Merkler D, Lyons DA, et al. 2014. Myelin membrane wrapping of CNS axons by $\mathrm{PI}(3,4,5) \mathrm{P} 3$-dependent polarized growth at the inner tongue. Cell 156: 277-290.

Sobottka B, Ziegler U, Kaech A, Becher B, Goebels N. 2011. CNS live imaging reveals a new mechanism of myelination: The liquid croissant model. Glia 59: 1841-1849.

Somjen GG. 1988. Nervenkitt: Notes on the history of the concept of neuroglia. Glia 1:2-9.

Taveggia C, Feltri ML, Wrabetz L. 2010. Signals to promote myelin formation and repair. Nat Rev Neurol 6: 276-287.

Tawk M, Makoukji J, Belle M, Fonte C, Trousson A, Hawkins T, Li H, Ghandour S, Schumacher M, Massaad C. 2011. $\mathrm{Wnt} / \beta$-catenin signaling is an essential and direct driver of myelin gene expression and myelinogenesis. J Neurosci 31: $3729-3742$.

Toyama BH, Savas JN, Park SK, Harris MS, Ingolia NT, Yates JR III, Hetzer MW. 2013. Identification of long-lived proteins reveals exceptional stability of essential cellular structures. Cell 154: 971-982.

Trapp BD, Nishiyama A, Cheng D, Macklin W. 1997. Differentiation and death of premyelinating oligodendrocytes in developing rodent brain. J Cell Biol 137: 459468.

Tyler WA, Gangoli N, Gokina P, Kim HA, Covey M, Levison SW, Wood TL. 2009. Activation of the mammalian target of rapamycin (mTOR) is essential for oligodendrocyte differentiation. J Neurosci 29: 6367-6378.

Umemori H, Sato S, Yagi T, Aizawa S, Yamamoto T. 1994. Initial events of myelination involve Fyn tyrosine kinase signalling. Nature 367: 572-576.

Velumian AA, Samoilova M, Fehlings MG. 2011. Visualization of cytoplasmic diffusion within living myelin sheaths of CNS white matter axons using microinjection of the fluorescent dye Lucifer Yellow. Neuroimage 56: $27-34$.

Wake H, Lee PR, Fields RD. 2011. Control of local protein synthesis and initial events in myelination by action potentials. Science 333: 1647-1651.

Watkins TA, Emery B, Mulinyawe S, Barres BA. 2008. Distinct stages of myelination regulated by $\gamma$-secretase and astrocytes in a rapidly myelinating CNS coculture system. Neuron 60: 555-569.

Wegner M. 2008. A matter of identity: Transcriptional control in oligodendrocytes. J Mol Neurosci 35: 3-12.

Werner HB, Kuhlmann K, Shen S, Uecker M, Schardt A, Dimova K, Orfaniotou F, Dhaunchak A, Brinkmann BG, Mobius W, et al. 2007. Proteolipid protein is required for transport of sirtuin 2 into CNS myelin. J Neurosci 27: $7717-7730$.

White R, Gonsior C, Kramer-Albers EM, Stohr N, Huttelmaier S, Trotter J. 2008. Activation of oligodendroglial Fyn kinase enhances translation of mRNAs transported 
Oligodendrocytes: Myelination and Axonal Support

in hnRNP A2-dependent RNA granules. J Cell Biol 181: 579-586.

Young KM, Psachoulia K, Tripathi RB, Dunn SJ, Cossell L, Attwell D, Tohyama K, Richardson WD. 2013. Oligodendrocyte dynamics in the healthy adult CNS: Evidence for myelin remodeling. Neuron 77: 873-885.

Zhao X, He X, Han X, Yu Y, Ye F, Chen Y, Hoang T, Xu X, Mi QS, Xin M, et al. 2010. MicroRNA-mediated control of oligodendrocyte differentiation. Neuron 65: 612-626.

Zoller I, Meixner M, Hartmann D, Bussow H, Meyer R, Gieselmann V, Eckhardt M. 2008. Absence of 2hydroxylated sphingolipids is compatible with normal neural development but causes late-onset axon and myelin sheath degeneration. J Neurosci 28: 97419754. 


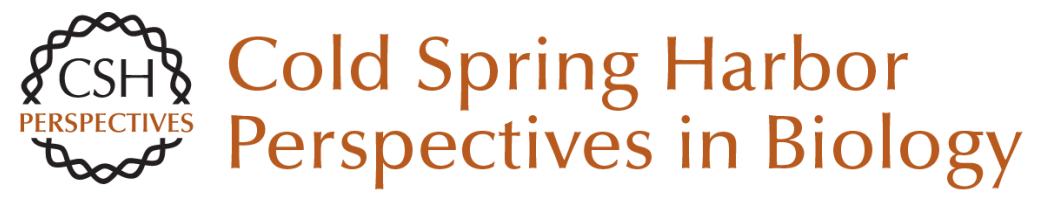

\section{Oligodendrocytes: Myelination and Axonal Support}

Mikael Simons and Klaus-Armin Nave

Cold Spring Harb Perspect Biol 2016; doi: 10.1101/cshperspect.a020479 originally published online June 22, 2015

\section{Subject Collection Glia}

The Nodes of Ranvier: Molecular Assembly and Maintenance

Matthew N. Rasband and Elior Peles

Microglia in Health and Disease

Richard M. Ransohoff and Joseph El Khoury

The Astrocyte: Powerhouse and Recycling Center Bruno Weber and L. Felipe Barros

Microglia Function in Central Nervous System

Development and Plasticity

Dorothy P. Schafer and Beth Stevens

Transcriptional and Epigenetic Regulation of Oligodendrocyte Development and Myelination in the Central Nervous System

Ben Emery and Q. Richard Lu

Origin of Microglia: Current Concepts and Past

Controversies

Florent Ginhoux and Marco Prinz

Glia Disease and Repair--Remyelination

Robin J.M. Franklin and Steven A. Goldman

Astrocytes in Neurodegenerative Disease

Hemali Phatnani and Tom Maniatis
Oligodendrocyte Development and Plasticity Dwight E. Bergles and William D. Richardson

Oligodendrocytes: Myelination and Axonal

Support Mikael Simons and Klaus-Armin Nave

Drosophila Central Nervous System Glia Marc R. Freeman

Perisynaptic Schwann Cells at the Neuromuscular

Synapse: Adaptable, Multitasking Glial Cells Chien-Ping Ko and Richard Robitaille

Astrocytes Control Synapse Formation, Function, and Elimination Won-Suk Chung, Nicola J. Allen and Cagla Eroglu

Schwann Cell Myelination James L. Salzer

Schwann Cells: Development and Role in Nerve Repair

Kristján R. Jessen, Rhona Mirsky and Alison C. Lloyd

Perineurial Glia

Sarah Kucenas

For additional articles in this collection, see http://cshperspectives.cshlp.org/cgi/collection/

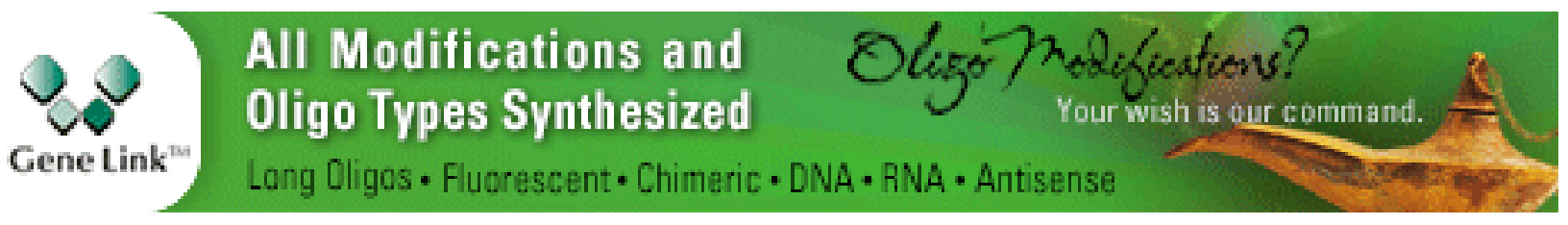

